\title{
The Application of an Evolutionary Programming Process to a Simulation of the ETEX Large-Scale Airborne Dispersion Experiment
}

\author{
David Werth, Grace Maze, Robert Buckley, AND STeVen Chiswell \\ Savannah River National Laboratory, Aiken, South Carolina
}

(Manuscript received 10 April 2018, in final form 1 November 2018)

\begin{abstract}
Airborne tracer simulations are typically performed using a dispersion model driven by a high-resolution meteorological model. Besides solving the dynamic equations of momentum, heat, and moisture on the resolved model grid, mesoscale models must account for subgrid-scale fluxes and other unresolved processes. These are estimated through parameterization schemes of eddy diffusion, convection, and surface interactions, and they make use of prescribed parameters set by the user. Such "free" model parameters are often poorly constrained, and a range of plausible values exists for each. Evolutionary programming (EP) is a process to improve the selection of the parameters. A population of simulations is first run with a different set of parameter values for each member, and the member judged most accurate is selected as the "parent" of a new "generation." After a number of iterations, the simulations should approach a configuration that is best adapted to the atmospheric conditions. We apply the EP process to simulate the first release of the 1994 European Tracer Experiment (ETEX) project, which comprised two experiments in which a tracer was released in western France and sampled by an observing network. The EP process is used to improve a simulation of the RAMS mesoscale weather model, with weather data collected during ETEX being used to "score" the individual members according to how well each simulation matches the observations. The meteorological simulations from before and after application of the EP process are each used to force a dispersion model to create a simulation of the ETEX release, and substantial improvement is observed when these are validated against sampled tracer concentrations.
\end{abstract}

\section{Introduction}

The use of computers to simulate the dispersion of an airborne contaminant is a fundamental component of modern emergency planning. Emergency managers must be prepared to respond to an accidental or deliberate release, and to do that they require information about the spatial and temporal migration of the gaseous material. This can involve not only small-scale releases, but larger-scale releases in which airborne material will travel across a continent from its release point. To study the latter process, the European Tracer Experiment (ETEX) was conducted in October and November of 1994 (van Dop et al. 1998). ETEX comprised two largescale releases (one in each month) of a tracer from western France, and its subsequent transport across Europe by the prevailing westerly winds. Meteorological observations and tracer concentrations were recorded across Europe during the experiment, with 168

Corresponding author: David Werth, david.werth@srnl.doe.gov detectors recording concentrations over a 3-day period, and the resulting database has proven valuable for validating tracer transport simulations (e.g., Straume 2001; Galmarini et al. 2004).

Such simulations are usually performed with an airborne dispersion model forced with the results from a mesoscale weather model. The latter solves for the equations of motion on a resolved grid, but must make use of schemes to solve for unresolved quantities. These "parameterizations" make use of prescribed settings (parameters), which the user must select from within a range of plausible values. Users must select a convective and a boundary layer scheme (Stensrud et al. 2000), the strength that the prescribed external boundary values influence the model grid, and the values that dictate the way that the model simulates subgrid-scale turbulent transfer of momentum and heat (Walko and Tremback 2006), as well as setting initial values of soil moisture and temperature (typically not available). The final result can be sensitive to these parameters (Stensrud et al. 2000), and this will lead to significant error in a 
dispersion simulation forced with mesoscale model output (Lucas et al. 2017).

Evolutionary programming (EP) is based on the premise that a particular (but unknown) set of parameters for a model will yield a best simulation (or forecast), and the goal is to find that set (Jones 2002; O'Steen and Werth 2009; Roebber 2015; Duan et al. 2017). If we define a parameter space (Fig. 1) of all possible parameter sets $x_{i}$, each point in this space will produce a model result with an objective error $E$ when validated against observations [as on the hypothetical surface $E=f\left(x_{1}, x_{2}\right)$ in Fig. 1], and the goal of modelers is to find the parameter set (i.e., the point in the parameter space) for which $E$ is at its minimum. To get an "optimized" model simulation, one could manually run a large number of simulations with different parameter sets (Severijns and Hazeleger 2005; Duan et al. 2017), but a more efficient approach would be to apply a computerized search algorithm to systematically explore the parameter space-validating simulations run with various parameter sets, and using the results to select new points in the parameter space to explore (Civicioglu 2013). Duan et al. (2017), for example, applied "automatic model calibration"-running a numerical weather model with multiple parameter sets and selecting new points to explore the most promising regions of the parameter space-and found great improvement in their numerical precipitation forecasts. Severijns and Hazeleger (2005) applied the "downhill simplex minimization" to the problem of optimizing a global climate model. In that process, a set of points is evaluated, and the worst-scoring point is replaced with a new point close to the best scoring.

As defined by Jones (2002), EP involves the creation of an initial "population" of solutions, the evaluation of each of them using an objective measure, the creation of a new generation through the "mutation" of one or more of the members, and the repetition of the process, with each generation ideally representing an improvement upon the last. The process is similar to the downhill simplex method in that increasingly better solutions are selected, but in EP, all members of the population but one (the best scoring) are replaced. O'Steen and Werth (2009) applied an EP algorithm to improve a mesoscale simulation of the western United States and saw large reductions in model bias over the domain. This improvement was realized despite the use of data from only one station for scoring.

Others have done similar experiments applying a "genetic" programming process-adding the genetic mechanisms of crossover and transposition to the mutation process to create a new generation. Bakhshaii and Stull (2009) showed how such a genetic algorithm

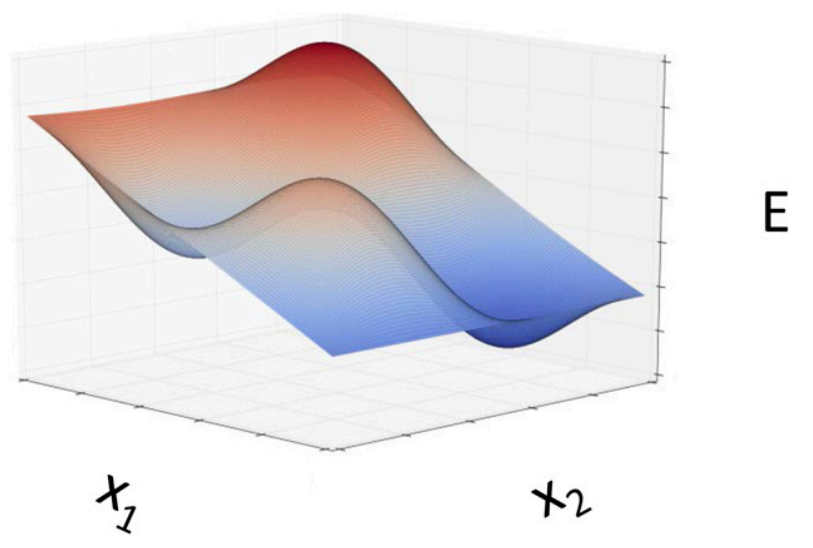

FIG. 1. Schematic of an idealized two-dimensional parameter space that defines the error $E$ of a model run with any set of parameters $\left(x_{1}, x_{2}\right)$.

can be used to optimize the function used to combine the individual members of an ensemble of numerical weather forecasts. Haupt (2005) applied a genetic algorithm to the problem of determining which distribution of source release rates minimized the differences between observed and modeled concentrations at a receptor, and in several cases studied, the allocation of emissions to the sources was very accurate.

Our goal is to improve a tracer simulation of the first ETEX release (ETEX-1, done in October 1994) by optimizing a numerical weather model that will subsequently be used to force a tracer simulation of that release. We will apply a search algorithm by which points in the parameter space are evaluated, and a path from an initial point to a final (better) point in that space is determined. To do this, we make small perturbations about the current "best" point and evaluate each to determine the direction of motion. In this sense, it is similar to the automatic model calibration done by Duan et al. (2017) in that we will explore new parameter sets that are in close proximity to the point in the parameter space known to score well. We want the new members of the next generation to be entirely different from the members of the previous generation, so we choose to rely solely on mutation to create each new generation (with a procedure to increase the magnitude of the perturbations to escape a local minimum), which makes large deviations from the current, best point unlikely. Even if the members of each generation are similar, however, there should be enough difference among them to cause one to be slightly better than the others, and that by selecting the best repeatedly, we will finish the process with a simulation that is substantially better than the one with which we started. 


\section{Model simulation}

We first apply the EP process to improve a mesoscale simulation of the ETEX meteorology, and then we use the output to force an airborne dispersion model that uses the ETEX release location as a source. The EP selection process uses only a small subset of the meteorological data, and we determine if this translates into an improvement of 1) the meteorological simulation as a whole and 2) the coupled dispersion simulation as validated against ETEX tracer data.

\section{a. RAMS}

The meteorological component of the modeling is performed with the Regional Atmospheric Modeling System (RAMS; Pielke et al. 1992; Cotton et al. 2003), a three-dimensional, finite-difference numerical model that has been tested and used to study a wide variety of atmospheric motions ranging in size from synoptic-scale phenomena, such as cyclones and hurricanes, to large-eddy simulations (Cotton et al. 2003). It has also been used in dispersion simulations (Calastrini et al. 2012; Werth et al. 2017; Wang et al. 2017), including continental scale (Werth and Buckley 2017). Basic features of the model include the use of nonhydrostatic, compressible equations and a terrainfollowing coordinate system with variable vertical resolution. The model is run with two grids-an outer grid at $60-\mathrm{km}$ grid spacing and an inner grid at $20-\mathrm{km}$ grid spacing, centered in central Germany $\left(52^{\circ} \mathrm{N}, 10^{\circ} \mathrm{E}\right)$. The inner grid (Fig. 2) comprises $125 \times 98$ grid points and encompasses the locations of the ETEX sensors and source point. The model is run with 37 vertical levels that start with a 50-m-thick layer at the surface and increases with each successive level until a maximum thickness of $1000 \mathrm{~m}$ is reached, with the model top at $22.3 \mathrm{~km}$.

Boundary and initial conditions are taken from the Climate Forecast System (CFS) model, run with $0.5^{\circ}$ horizontal grid spacing (Saha et al. 2010) and updated every $6 \mathrm{~h}$. A relaxation scheme is applied to "nudge" each interior grid to its respective outer grid, according to values set by the user (Walko and Tremback 2006). The model surface fluxes are parameterized using a soil model that comprises 13 levels, extending to a total depth of $1 \mathrm{~m}$. This model predicts sensible and latent heat fluxes, both between layers and through the surface, using a vegetation parameterization developed by Walko et al. (2000). The USGS vegetation data used are defined at $\sim 1-\mathrm{km}$ horizontal resolution, using AVHRR data from 1992 to 1993. Sea surface temperatures are obtained from monthly climatological data at $1.0^{\circ}$ horizontal grid resolution (Reynolds et al. 2002) and interpolated

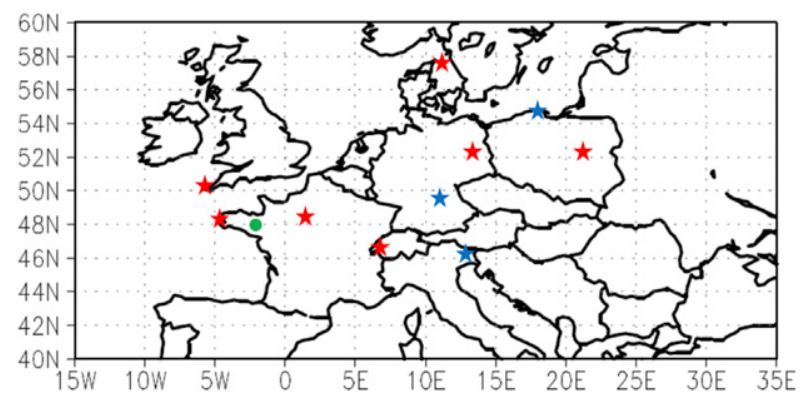

FIG. 2. Map showing the grid-2 model domain, along with the locations of the observed meteorological soundings (stars) used in the evaluation of the EP members. The blue stars indicate stations added after generation 51, and the green circle represents the source location.

between successive months to create a prescribed annual cycle. The model grid topography is calculated with 30 -s (roughly $800-\mathrm{m}$ )-resolution topographic data to create the total topographic forcing (appendix A). The time span for the simulations is 0000 UTC 23 October0000 UTC 27 October 1994, encompassing the period of the ETEX-1 release.

The model uses the Harrington radiation scheme for shortwave and longwave absorption and reradiation (Harrington 1997). Subgrid-scale vertical turbulent diffusion is parameterized with the Mellor-Yamada scheme (Mellor and Yamada 1982), and horizontal diffusion is accomplished with the Smagorinsky (1963) deformation scheme. The Mellor-Yamada model calculates a turbulent kinetic energy (TKE) budget, which is subsequently applied to calculate vertical turbulent transport in the dispersion model.

\section{b. HYSPLIT}

The first ETEX release was a continuous surface emission of $340 \mathrm{~kg}$ of perflouomethylcyclohexane $(\mathrm{PMCH}$, an inert gas) from Monterfil, France $\left(48.06^{\circ} \mathrm{N}, 2.01^{\circ} \mathrm{W}\right)$. The release started at 1600 UTC 23 October 1994 and continued until 0350 UTC 24 October with an average release rate of $8.0 \mathrm{~g} \mathrm{~s}^{-1}$ (Girardi et al. 1998). The airborne dispersion is simulated using the Hybrid SingleParticle Lagrangian Integrated Trajectory model (HYSPLIT; Draxler and Hess 1998), using as input the mesoscale model data and a prescribed source term. HYSPLIT has been used in numerous applications related to the large-scale dispersion of emitted tracer (e.g., Yerramilli et al. 2012; Stunder et al. 2007; Wang et al. 2017; Yumimoto et al. 2009). This Lagrangian model simulates the release of a large number of "particles," recalculating at each time step the position of each one according to both a resolved wind field (from the mesoscale model), as well as a dispersive term 
TABLE 1. Parent input parameters for the evolutionary programming base case and for generation 80 (see appendix A for details).

\begin{tabular}{|c|c|c|c|}
\hline Variable & Comment & Base case & Generation 80 \\
\hline AKMIN, grid 1 & Controls subgrid-scale mixing, grid 1 & 2 & 1.4597 \\
\hline TNUDLAT & Nudging time at boundary (s) & 1350 & 1425.6 \\
\hline TNUDCENT & Nudging time at center of domain (s) & 10800 & 9746.5 \\
\hline SLMSTR & Initial soil moisture & 0.3 & 0.4 \\
\hline STGOFF & Initial soil temperature, offset (K) & 2 & -2.9 \\
\hline AKMIN, grid 2 & Controls subgrid-scale mixing, grid 2 & 1 & 0.5137 \\
\hline TOPTENH & Controls subgrid-scale topography & 0.5 & 0.19081 \\
\hline TOPTWVL & Wavelength cutoff for topography & 4 & 5.2876 \\
\hline$L$ & Length-scale multiplier controlling subgrid-scale vertical mixing & 1 & 3.2868 \\
\hline
\end{tabular}

derived from simulated TKE from the mesoscale model (allowing for motions at scales smaller than the resolution of meteorological data used to force it). The particles begin at the release point as a concentrated cloud, which are dispersed and transported downwind as the simulation progresses. The horizontal concentration grid spacing used in HYSPLIT was $0.1^{\circ} \times 0.1^{\circ}$ (roughly $10 \mathrm{~km}$ ) with a vertical grid containing 32 levels up to $15 \mathrm{~km}$ (with a 10-m layer at the bottom, and each successive level increasing in thickness).

\section{c. Evolutionary programming}

\section{1) INITIAL PROCESS}

EP involves the creation of a population of members, each of which is run with variations in its model physics (Eckel and Mass 2005; Berner et al. 2011). To start the process, an initial population of 10 RAMS simulations is created, each member of which is run with a different set of model parameters that control the way the model calculates unresolved and other nonexplicit quantities (Table 1; see appendix A for a detailed description of the perturbed parameters). The first generation is created using a base case (Table 1) as member 1, and randomly perturbing the parameter values about these values for each of members 2-10. The base case represented plausible values that tended to be in the midrange of the recommended values, providing a good standard against which we can gauge the value of EP in improving the simulation. After completing, each member is "scored" by validating it against the observed meteorology, the "winner" (possibly the parent of the current generation) is selected to serve as the parent of the next generation by perturbing its model parameters to create a new 10 -member population, and the entire process is repeated. The scores are monitored as the successive simulations are generated, and after 80 generations, we decided to terminate the process and determine if the improvements in the scores were reflected in improvements of the coupled RAMS-HYSPLIT simulation.
The total parameter space (the domain) is defined as all the values between a set minimum and a set maximum along each axis (Table 2). To create each member of the new generation, a point along each axis is randomly selected within a prescribed distance from the parent point. (That is, a point is randomly selected from the region within a nine-dimensional hyperrectangle centered at the parent point.) The length of each side is initially set to be $1 / 8$ of the total axis length, keeping the perturbed members relatively close to their parent in the hope of finding a nearby, improved member. This was automatically adjusted, however, if the parent of a generation outscored all the other members, suggesting the current best solution was trapped in a local minimum. When this occurred, the range of values for the next generation was increased by a prescribed percentage, forcing the members of the subsequent generation further from their parent in an attempt to find a new, more remote minimum. (If a new parent is selected for the following generation, the $1 / 8$ value was restored.) Running on 30 computer nodes per member, each generation requires about $8 \mathrm{~h}$ to complete.

To score the members, their respective results are compared to meteorological data recorded during the ETEX release through a series of weather balloon launches, allowing us to make use of data throughout the boundary layer. Dozens of soundings exist over the domain for this period, but we want to determine if using

TABLE 2. Ranges of permissible parameter values.

\begin{tabular}{lcc}
\hline \hline \multicolumn{1}{c}{ Variable } & Initial range & $\begin{array}{c}\text { Range from } \\
\text { generation 41 to 67 }\end{array}$ \\
\hline AKMIN, grid 1 & $0.1-2$ & $0.1-2$ \\
TNUDLAT (s) & $900-1800$ & $900-1600$ \\
TNUDCENT (s) & $7200-14400$ & $7200-13000$ \\
SLMSTR & $0.15-0.80$ & $0.15-0.40$ \\
STGOFF (K) & -5 to 5 & -5 to 5 \\
AKMIN, grid 2 & $0.1-2$ & $1.25-1.75$ \\
TOPTENH & $0.1-0.9$ & $0.3-0.5$ \\
TOPTWVL & $4.0-6.0$ & $4.0-4.5$ \\
$L$ & $1-8$ & $1.5-4$ \\
\hline
\end{tabular}


data from a small number of stations for scoring can lead to an improvement in the model performance over the larger model domain (and that the process was not merely leading to improvement only at a few locations), so only a subset of the observations is used for scoring. The remainder will be used to gauge how well the model simulation improved overall. For each member, a profile of the simulated meteorological values is generated at each of the selected observation sounding locations (seen in Fig. 2). Given the focus on near-surface transport, the simulation profiles were limited to below $900 \mathrm{hPa}$ (about $900 \mathrm{~m}$ above ground) to penalize simulations with large errors close to the ground. The observed profiles from those same locations were then searched to find data at matching times (every hour between 1600 UTC 23 October and 0000 UTC 27 October) and pressure levels (the latter through interpolation, with useable observations at about five points between the surface and $900 \mathrm{hPa})$, and the score was the total root-mean-square errors (RMSEs) of zonal wind speed $u$, meridional wind speed $v$, and temperature $T$, calculated over all stations, observation times, and levels in the boundary layer.

\section{2) Alterations}

EP requires some subjective decisions be made. O'Steen and Werth (2009), for example, had to make changes to their scoring algorithm when a persistent bias arose. In our simulations, changes in the parameters and their associated scores were monitored during the process, and periods during which no improvement in the score of the best member often occurred, despite searching increasingly distant locations for a new minimum. During these periods, various changes to the procedure were made to refocus the search.

(i) Sounding locations used for scoring. At generation 51 , the number of sounding locations over which the score was calculated was increased from 7 to 10 (Fig. 2), for a more rigorous metric of simulation quality.

(ii) Selecting new parameter values. At generation 41, the range of permissible parameters values was reduced to decrease the size of the domain (Table 2) and focus the search on a smaller region surrounding the current best point. At generation 68, however, the original ranges were restored. When a new generation failed to produce an improved member, the prescribed increase in radius was set at $11 \%$ up to generation 60 , when we adjusted it to $1 \%$ to narrow the search to an area closer to the parent.

(iii) Scoring. To establish greater selection pressure against simulations with large wind speed and direction errors, the score was refigured after 66 generations as a

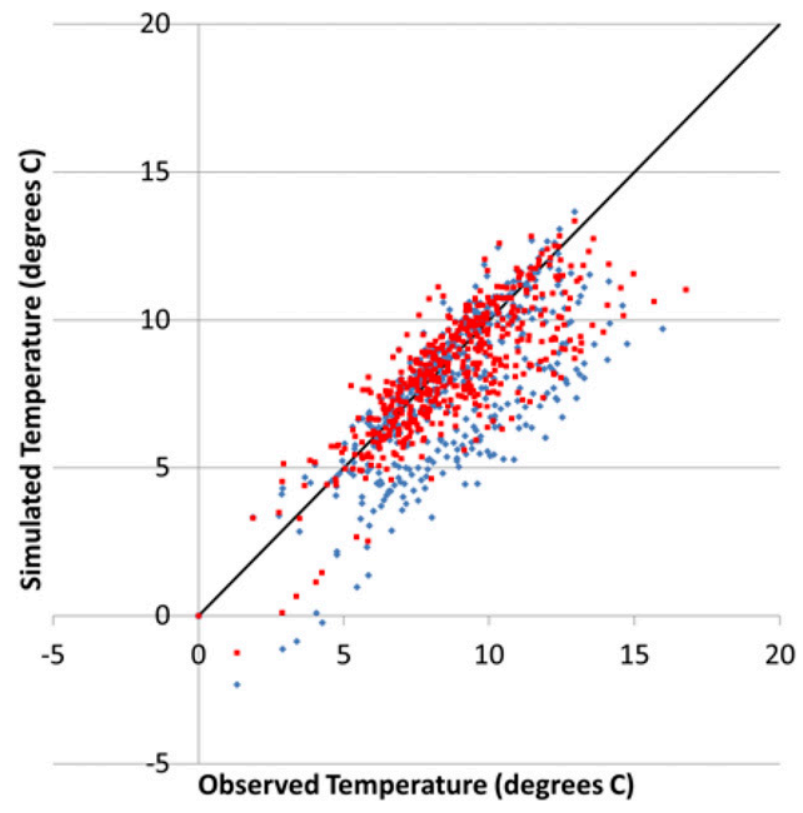

FIG. 3. Scatterplot comparing the observed and simulated temperatures (each point represents a comparison of a single station for a single time at a single level in the boundary layer) for the base case (blue) and generation 80 (red).

sum of the temperature RMSE, the absolute speed RMSE, and one-half of the direction RMSE (the latter because directional errors in degrees are much larger than the other two errors).

\section{d. WRF ensemble}

The first ETEX release was also simulated using the Weather Research and Forecasting (WRF) Model, making use of a standard technique for producing an ensemble of simulations, and we use data from that experiment as a baseline to which we can compare the results of the EP simulations done with RAMS. WRF is a three-dimensional, fully nonhydrostatic, finitedifference numerical weather prediction model that has been jointly developed for use in both research and operational atmospheric simulation applications (Skamarock et al. 2008). Basic features of the model include the use of fully compressible nonhydrostatic equations that are conservative for scalar variables, and a terrain-following coordinate system with variable vertical resolution and vertical grid stretching. The WRF simulations were conducted using the Mellor-Yamada-Nakanishi-Niino level 2.5 PBL physics and surface-layer schemes (Nakanishi and Niino 2004, 2006), the Goddard radiation scheme (Chou and Suarez 1999), the Grell 3D ensemble cumulus parameterization scheme (Grell 1993; Grell and Devenyi 2002), the Lin microphysics scheme (Lin et al. 1983), and the 
TABLE 3. Validation of the RAMS simulation, calculated over the same 10 locations used for scoring (shown in Fig. 2) at all times and levels (below $900 \mathrm{hPa}$ ) at which an observation and corresponding model data points exist. Values in boldface font under generation 80 (Gen 80) indicate improvement over the base case. RMSE values for wind direction are calculated using the angle between the observed and simulated wind directions, going clockwise or counterclockwise according to which provided the smaller value.

\begin{tabular}{lrr}
\hline \hline & Base Case & Gen 80 \\
\hline Correlation & & \\
Temperature $\left({ }^{\circ} \mathrm{C}\right)$ & 0.71 & $\mathbf{0 . 7 9}$ \\
Speed $\left(\mathrm{m} \mathrm{s}^{-1}\right)$ & 0.88 & $\mathbf{0 . 9 0}$ \\
Direction $\left({ }^{\circ}\right)$ & 0.77 & $\mathbf{0 . 7 8}$ \\
RMSE & & \\
Temperature $\left({ }^{\circ} \mathrm{C}\right)$ & 2.05 & $\mathbf{1 . 5 4}$ \\
Speed $\left(\mathrm{m} \mathrm{s}^{-1}\right)$ & 2.10 & $\mathbf{1 . 7 5}$ \\
Direction $\left({ }^{\circ}\right)$ & 21.88 & $\mathbf{2 1 . 1 1}$ \\
Bias & & $\mathbf{- 0 . 5 1}$ \\
Temperature $\left({ }^{\circ} \mathrm{C}\right)$ & -0.99 & $\mathbf{0 . 1 0}$ \\
Speed $\left(\mathrm{m} \mathrm{s}^{-1}\right)$ & 0.80 & $\mathbf{- 4 . 4 6}$ \\
Direction $\left({ }^{\circ}\right)$ & -4.72 & \\
\hline
\end{tabular}

unified Noah land surface model scheme (Tewari et al. 2004). Twenty ensemble members were generated using a technique described in Berner et al. (2011) - a stochastic perturbation to each WRF simulation was generated using stochastic kinetic-energy backscatter (SKEBS; Shutts 2005). SKEBS introduces temporally and spatially correlated perturbations to the rotational wind components $u$ and $v$ and potential temperature $\theta$ after observations are resolved to the grid.

\section{Results}

\section{a. Meteorology}

By selecting progressively better parameter sets (defined by their ability to produce a more accurate RAMS simulation when validated at the 7-10 stations), we expect that the model variables will come to match observations at those stations. Given that three variables at 7-10 locations at several heights are used for scoring, however, it is possible that some of these values can become worse, so long as their prescribed aggregate becomes better. A scatterplot of simulated and observed temperatures at all levels and times for all 10 sounding locations used for scoring (Fig. 3) shows a cool bias at one of the stations for the RAMS simulation run with the base case values. After 80 generations, however, the best ${ }^{1}$ RAMS simulation was run with parameters that led

\footnotetext{
${ }^{1}$ All generation 80 results are given for the best-scoring member of the population.
}

TABLE 4. Scoring metrics of the RAMS simulation, calculated over the entire model domain with all available surface stations for wind direction, wind speed, and temperature. Gen 00 represents the base case, and the others represent the "winning" member of each generation. In each column, the ideal value is the value one would expect for a simulation that perfectly matches observations (see appendix B for more information). Units for bias are ${ }^{\circ}$ (direction), $\mathrm{m} \mathrm{s}^{-1}$ (speed), and ${ }^{\circ} \mathrm{C}$ (temperature).

\begin{tabular}{|c|c|c|c|c|c|}
\hline Model & MG & VG & NMSE & Bias & FOEX \\
\hline \multicolumn{6}{|c|}{ Wind direction } \\
\hline EP Gen 00 & 0.979 & 1.12 & $4.82 \times 10^{-2}$ & -0.59 & - \\
\hline EP Gen 10 & 0.960 & 1.14 & $4.83 \times 10^{-2}$ & -4.36 & - \\
\hline EP Gen 30 & 0.941 & 1.15 & $5.09 \times 10^{-2}$ & -8.10 & - \\
\hline EP Gen 60 & 0.943 & 1.15 & $4.96 \times 10^{-2}$ & -7.82 & - \\
\hline EP Gen 70 & 0.944 & 1.14 & $5.08 \times 10^{-2}$ & -7.74 & - \\
\hline EP Gen 80 & 0.933 & 1.14 & $4.98 \times 10^{-2}$ & -9.68 & - \\
\hline Ideal value & 1 & 1 & 0 & 0 & 0 \\
\hline \multicolumn{6}{|c|}{ Wind speed } \\
\hline EP Gen 00 & 1.243 & 1.57 & 0.773 & 1.798 & -14 \\
\hline EP Gen 10 & 1.146 & 1.51 & 0.675 & 1.473 & -9 \\
\hline EP Gen 30 & 1.052 & 1.48 & 0.588 & 1.102 & -2 \\
\hline EP Gen 60 & 1.058 & 1.47 & 0.593 & 1.131 & -3 \\
\hline EP Gen 70 & 1.088 & 1.49 & 0.619 & 1.242 & -4 \\
\hline EP Gen 80 & 0.989 & 1.48 & 0.544 & 0.795 & 1 \\
\hline Ideal value & 1 & 1 & 0 & 0 & 0 \\
\hline \multicolumn{6}{|c|}{ Temperature } \\
\hline EP Gen 00 & 0.999 & 1.000 & $4.60 \times 10^{-5}$ & -0.185 & 4 \\
\hline EP Gen 10 & 0.999 & 1.000 & $4.60 \times 10^{-5}$ & -0.386 & 9 \\
\hline EP Gen 30 & 0.997 & 1.000 & $5.03 \times 10^{-5}$ & -0.721 & 17 \\
\hline EP Gen 60 & 0.997 & 1.000 & $5.01 \times 10^{-5}$ & -0.730 & 17 \\
\hline EP Gen 70 & 0.998 & 1.000 & $4.60 \times 10^{-5}$ & -0.465 & 9 \\
\hline EP Gen 80 & 0.998 & 1.000 & $4.88 \times 10^{-5}$ & -0.612 & 13 \\
\hline Ideal value & 1 & 1 & 0 & 0 & 0 \\
\hline
\end{tabular}

to a large reduction in this bias, as simulations with progressively warmer temperatures at this station were favored. Comparing the three variables (Table 3), the temperature experiences large improvement for three metrics of accuracy - the correlation increases, while the RMSE and bias decrease. For wind speed the correlation changes little, but with large decreases in RMSE and bias. The wind direction also experiences decreases in RMSE and bias, but on a more modest scale.

The soundings used for scoring represent a small subset of the weather data collected during ETEXdata were also collected at 168 surface stations across Europe. For a more complete picture of how the EP was improving the simulation, the meteorological simulations were evaluated over all surface stations (an independent dataset from the EP scoring) using five metrics of accuracy - the geometric mean bias (MG), the geometric variance (VG), the normalized mean square error (NMSE), the bias, and the factor of exceedance (FOEX) - and comparing the best member of each generation (see appendix B for details). 
a)

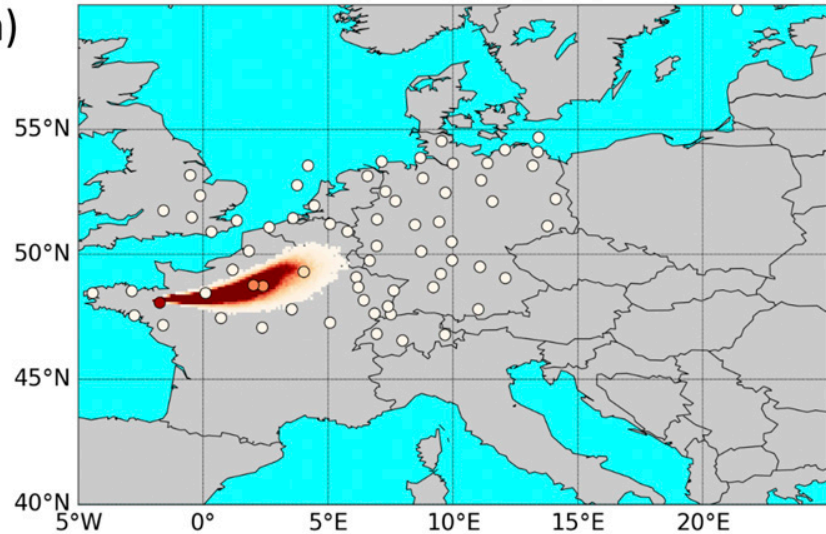

b)

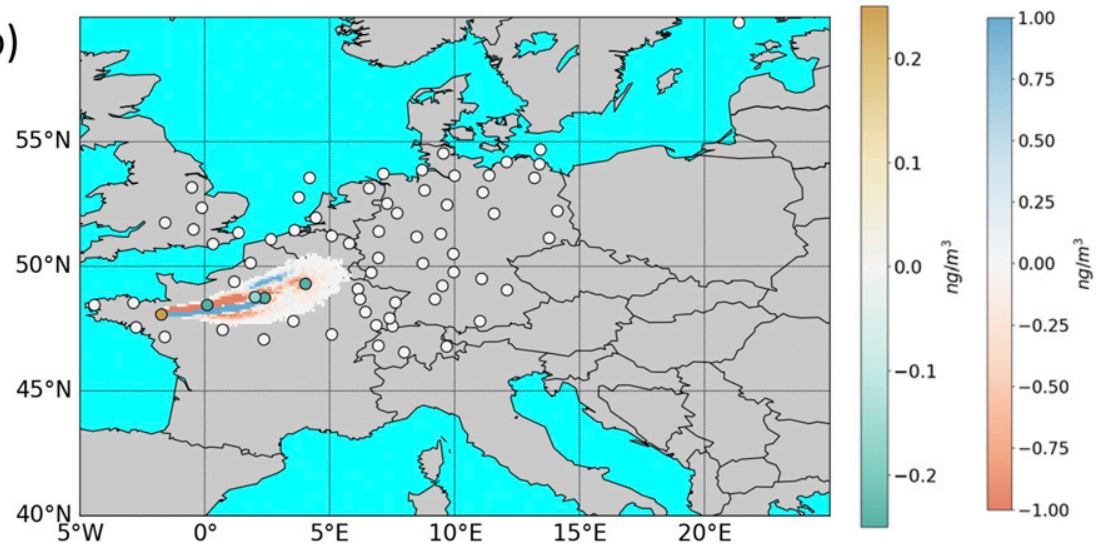

FIG. 4. (a) Simulated base-case tracer concentration after $12 \mathrm{~h}$ (shading), along with observed values at the monitoring stations (circles). (b) Concentration difference after $12 \mathrm{~h}$ between the generation 80 and base-case tracer simulations (shading; right color bar, with positive values indicating that generation 80 has greater values than the base case), along with the differences in error (circles; left color bar, with negative values in green indicating that the generation 80 errors are lower than for the base case.)

We see a trend of strong reduction of the largest errors, with small increases in the smallest errors, leading to an overall improvement (Table 4). For the base case, the wind speed has the largest errorscomparing MG, VG, and NMSE (all normalized metrics of error), the wind speed values are larger than those for wind direction or temperature, and the wind speed bias $\left(1.8 \mathrm{~m} \mathrm{~s}^{-1}\right)$ is large as well. After 80 generations, the wind speed shows much greater changes relative to the initial values than those for temperature and direction, and these lead to greatly improved scores for all five metrics. The metrics for temperature and direction actually degrade, implying that the improvement seen at the scoring stations (Table 3 ) did not lead to a similar improvement throughout the domain, but the changes are small relative to the improvement in wind speed. (For example, the wind speed NMSE improves by $42 \%$, while it gets worse for direction and temperature by $3 \%-5 \%$.) The wind speed metrics tend to degrade from generation 30 to generation 70 , but the change in scoring metric at generation 66 (which explicitly penalized wind speed errors) led to improved overall values by generation 80 .

\section{b. Dispersion}

In the base case simulation, the simulated plume moves eastward over the $48 \mathrm{~h}$ following the release (Figs. 4-7). After $12 \mathrm{~h}$, the plume is still confined to France (Fig. 4a), and has entered Germany after $24 \mathrm{~h}$ (Fig. 5a). After $36 \mathrm{~h}$, it is losing its "plume" shape in favor of a bow shape (Fig. 6a), which becomes longer and narrower after $48 \mathrm{~h}$, stretching along a northwestsoutheast axis from Denmark to Romania (Fig. 7a). At $12 \mathrm{~h}$ after initial release (Fig. 4a), errors in the simulation are more in the magnitude of the concentration, rather than in the plume location-all stations that indicate tracer are within the plume, but values in 

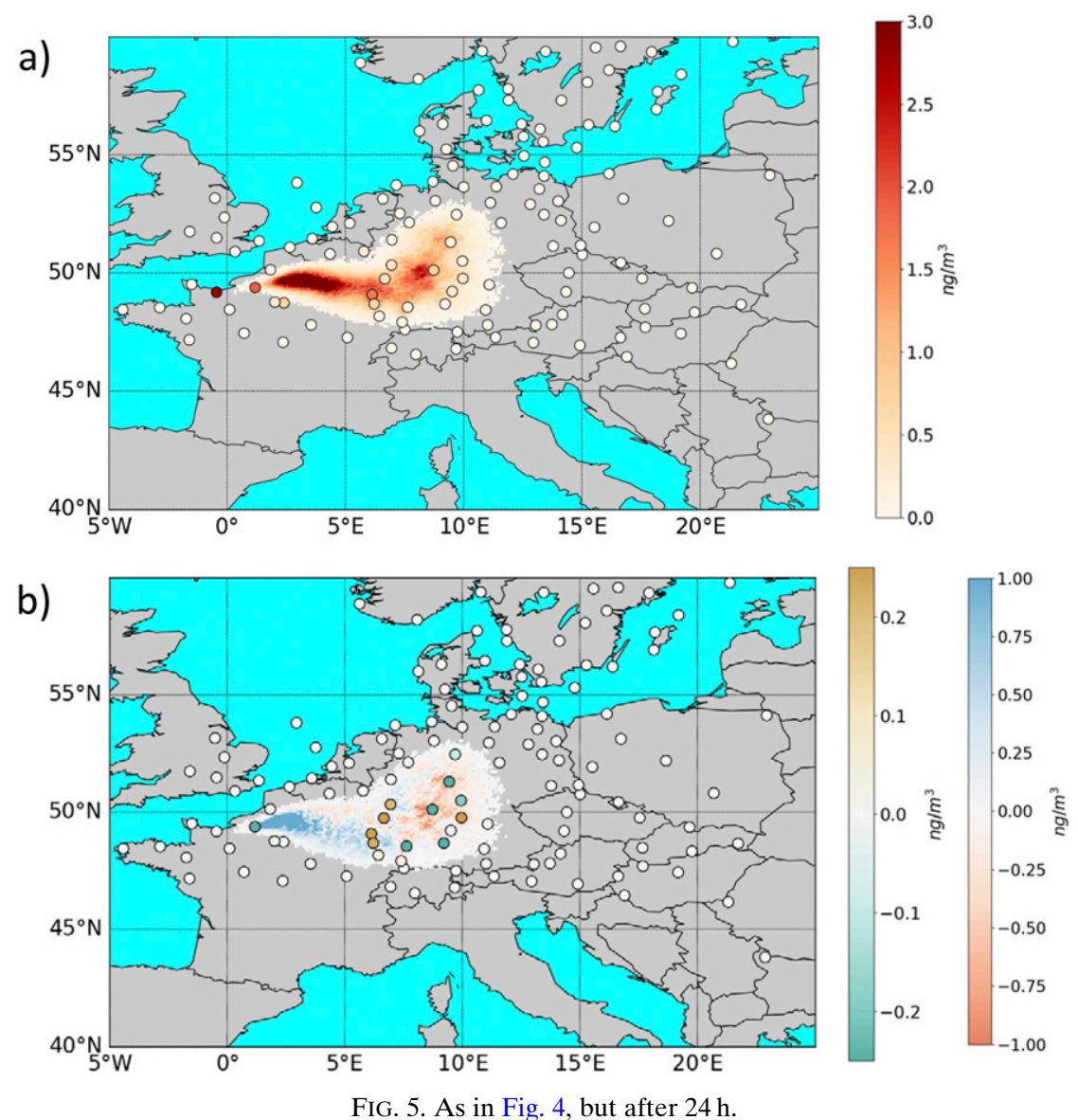

the plume "core" (the area of highest concentration) appear to be too high. At $24 \mathrm{~h}$ (Fig. 5a), stations registering tracer exist outside the plume, but there is generally good agreement between simulated and observed values within the plume. At $36 \mathrm{~h}$ (Fig. 6a), the simulated plume has outpaced the actual plume, with stations in Belgium detecting tracer despite the simulated plume having already passed this area. The plume also covers areas to the east (in eastern Germany and western Poland) where the stations tend to show no tracer. Judging by the station readings, the plume should have its westernmost point in Belgium, and its eastern end should not extend as far north as is simulated. Stations with little concentration also lie within the simulated core. The trend of too-rapid plume advection continues out to $48 \mathrm{~h}$ (Fig. 7a) - the simulated cloud has already passed areas where tracer still exists, and entered areas where none was yet detected. Within the plume, several stations with high $\left(>2.4 \mathrm{ng} \mathrm{m}^{-3}\right)$ concentration are outside the core and are instead lying on its fringes.

After 80 generations, the dispersion model is run again with the best member in the hope that the improved meteorological simulation will force a better dispersion simulation. After $12 \mathrm{~h}$ (Fig. 4b), the effect of the new simulation is to reduce plume dispersion-more tracer is confined to the central core, with less tracer downwind or to either side. Given that stations in the latter region were recording values that were lower than simulated, errors at those stations are reduced (indicated by circles in green). At $24 \mathrm{~h}$, more tracer has again been retained in the denser, upwind portion of the plume, with less being advected downwind into Germany (Fig. 5b). Errors have been reduced over the eastern stations that recorded values lower than simulated in the base-case simulation. Some stations near the French-German border were registering simulated concentrations that were too high, however, and the retention of more tracer over these stations in the generation 80 simulation has led to increased error.

This trend is continued at 36 and $48 \mathrm{~h}$ (Figs. 6b, 7b) - the plume motion is slowed, so that concentrations are higher in the upwind portion and lower in the downwind portion. Since the plume was moving too rapidly in the base case simulation, the effect of slowing it down is to reduce errors in the downwind (northeastern) portion of the simulated plume, which had been in reality beyond the plume's 
a)
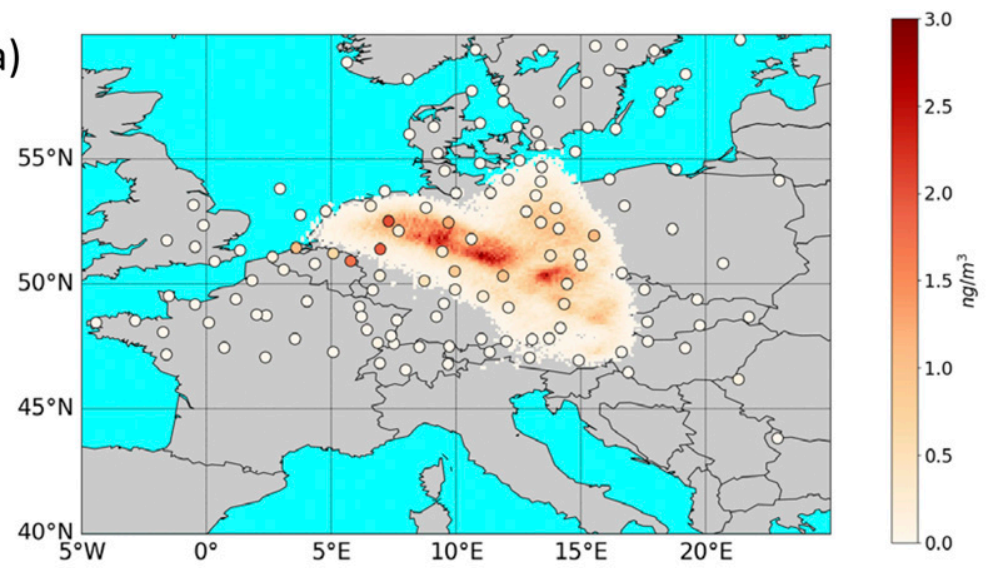

b)

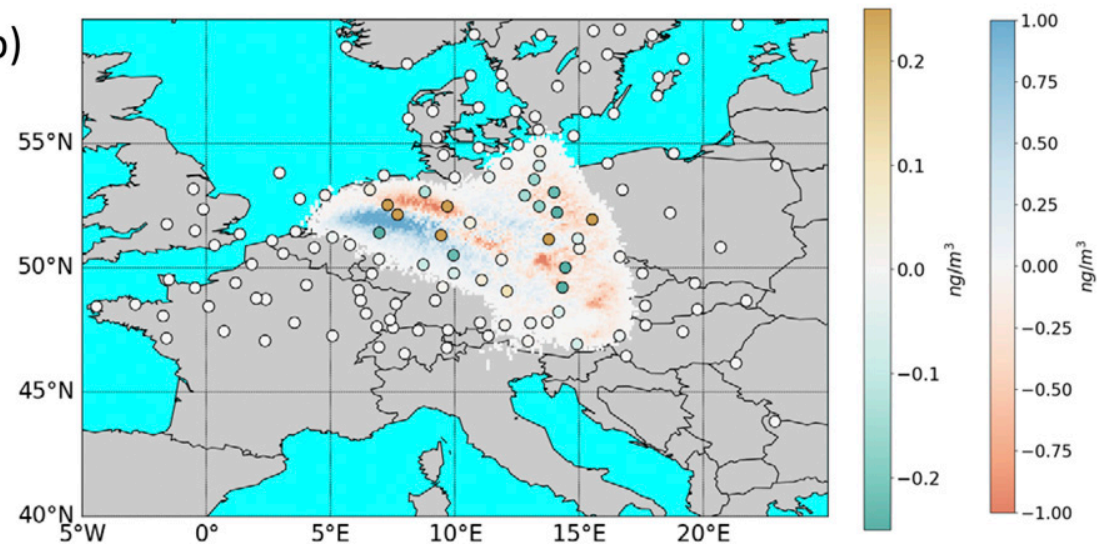

FIG. 6. As in Fig. 4, but after $36 \mathrm{~h}$.

easternmost edge. Some stations along the southwestern edge, however, experience greater errors in concentration as the higher simulated concentrations exceed what was observed.

Quantitatively, we can evaluate the dispersion simulations as a function of generation using four metrics-the correlation between the observed and simulated values, the VG score, the NMSE, and the bias (see appendix B for a description). When plotted as a function of generation (Figs. 8a-d), each metric demonstrates improvement-the correlation rises, while the other three metrics decrease toward their respective ideal values. The improvements are nonmonotonic (the NMSE and the bias reach a "best" value which then becomes worse by generation 80 ), and the quality of the simulations degraded between generations 30 and 60 (reflecting deterioration in the Table 4 speed metrics). For all these metrics, however, the final generation is better than the initial value, demonstrating the overall value of the evolutionary programming.

We can also compare these simulations to the results from the Atmospheric Transport Model Evaluation Study II (ATMES II; Mosca et al. 1998), which comprised an intercomparison of several model simulations of the
ETEX experiment, each from a different research group. Forty-nine separate simulations of the ETEX-1 tracer release were submitted to the ATMES II project, and the various models were ranked according to a composite score. When we calculate that same score for the different generations of the evolutionary programming runs and compare it to those from ATMES II (Fig. 8e), the EP ranking decreases from $27 / 50$ to $14 / 50$, rising from the 54th to the 28 th percentiles (with a reduction in ranking between generations 30 and 60, reflecting the degradation in the other Fig. 8 metrics). Two of the metrics-the NMSE and the ranking-start out worse than the WRF ensemble but have improved to better values by the last generation (Figs. 8b,e), highlighting further the magnitude of the improvement. While showing improvement, however, the RAMS-HYSPLIT bias remains worse than the WRF ensemble.

\section{c. Parameter evolution}

As designed here, the adjusted parameters vary by a small amount with each successive generation, and the point representing the position in the nine-dimensional phase space will slowly trace a path from the initial to the 

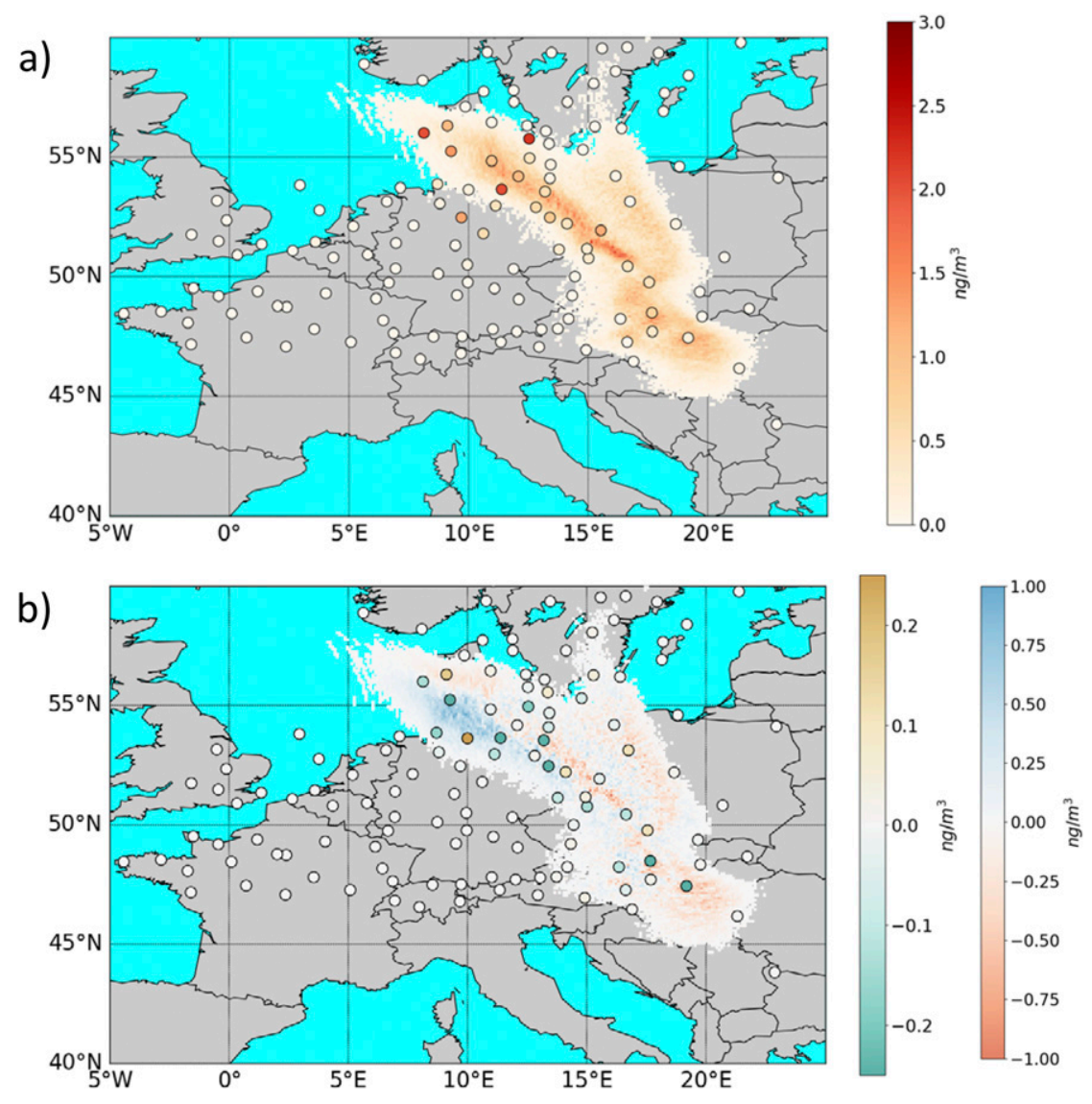

FIG. 7. As in Fig. 4, but after 48 h.

generation 80 values. We can therefore see what values are favored and how the model processes were being adjusted. For example, the optimized model is characterized by greater turbulence (Fig. 9a) - AKMIN values fall, which allows for greater variability in resolved horizontal winds and hence greater resolved turbulence, as the length-scale multiplier rises, raising the parameterized vertical mixing. The greater vertical turbulence led to reduced vertical gradients of wind velocity in the surface-to-900-hPa layer (not shown), and this redistribution of boundary layer wind led to vertical-mean winds that were slower overall.

The tendency for the topographic forcing is toward greater smoothing of topography (Fig. 9b) - the silhouetteaverage weighting is reduced (favoring the conventional averaging), and the minimum topographic wavelength is increased, both of which will lead to less shortwave topographic forcing. These changes imply that the initially higher-resolved topography was only degrading the model solution.

The path through the parameter space is not always toward the final solution-while the trend after 30 generations was to slightly decrease soil moisture and slightly increase the temperature offset (Fig. 9c), after 80 generations there is a clear tendency toward higher soil moisture initialization and temperature offsets that act to initialize the soil temperature to be cooler than the atmospheric surface temperature. This was likely due to the change from $u-v$ to direction-speed scoring at generation 67 , which precipitated sudden shifts in values of most of the parameters. We must also note that two of the parameters (TNUDLAT and TNUDCENT) changed little during the 80 generations, implying a weak effect on the model solution.

\section{Conclusions}

The use of the EP improved the model meteorology, both at the stations used for scoring the individual members and at other weather stations throughout the domain, and this translated into a greatly improved simulation of the ETEX tracer release experiment. It should be stressed this improvement in surface-based results (e.g., tracer concentrations) over the entire domain occurred by adapting the meteorological simulations to upper-air observations at several key 

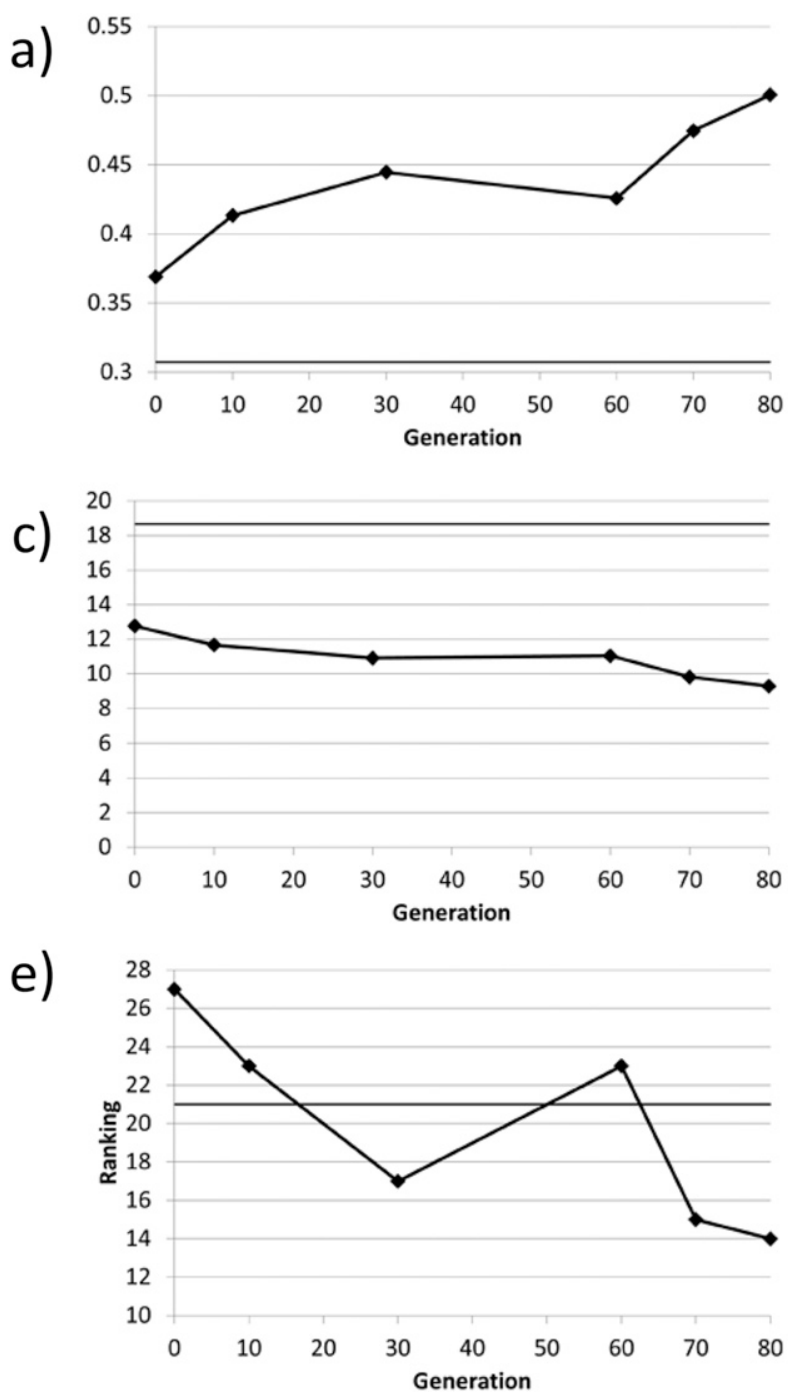

locations, up to almost $1 \mathrm{~km}$ above the ground. Its overall ranking among the ATMES II simulations was initially worse than that of a standard ensemble, but was better by generation 40 , and by generation 80 had moved into the top 14 of 50 models.

As was seen in O'Steen and Werth (2009), the process also required substantial user guidance, with the process adjusted several times in response to the population becoming trapped in a local minimum, which precluded further improvement. The latter phenomenon is a danger for any evolutionary process, and we did not completely avoid it by forcing greater "mutations" in the members during periods of nonimprovement. Altering the scoring and forcing the model to conform to data at more locations had the desired effect-ultimately, simulations created under these conditions were able to more accurately simulate tracer concentrations than those created before the changes. b)

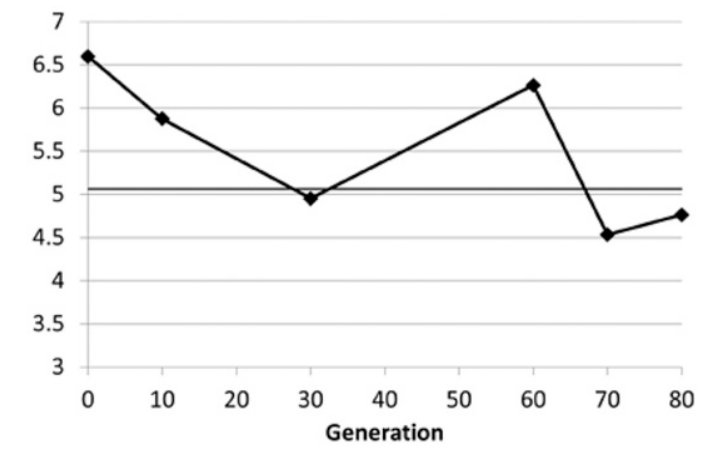

d)

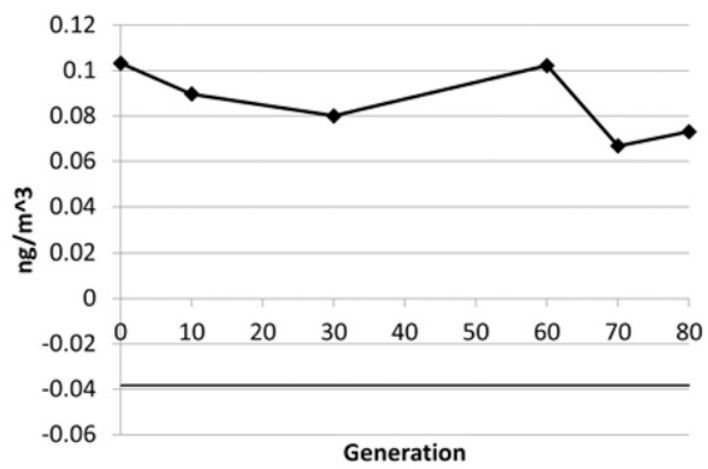

FIG. 8. Accuracy of simulated concentrations as a function of generation as measured by (a) correlation, (b) NMSE, (c) VG, (d) bias, and (e) ATMES II ranking. The thin black line represents the results for the best member of the WRF ensemble.
It is likely that any evolutionary process is similarly vulnerable, and should always be carefully monitored to detect and remedy such problems.

As applied here, the EP acted as a reanalysis tool, creating a complete set of meteorological fields that are consistent with a collection of observations. This makes it useful for the analysis of a past event, allowing us to determine concentrations at points that were not monitored or to identify from which of several potential source locations the tracer was released. Emergency management, however, often requires a rapid estimation of where the tracer from a current, ongoing release will migrate. The optimized parameters of one day may not be suitable for another. To address this, the EP could be applied to maintain a meteorological model by updating the model parameters each day, using the recent past as the standard for scoring. In this way, a mesoscale model adapted to current conditions 

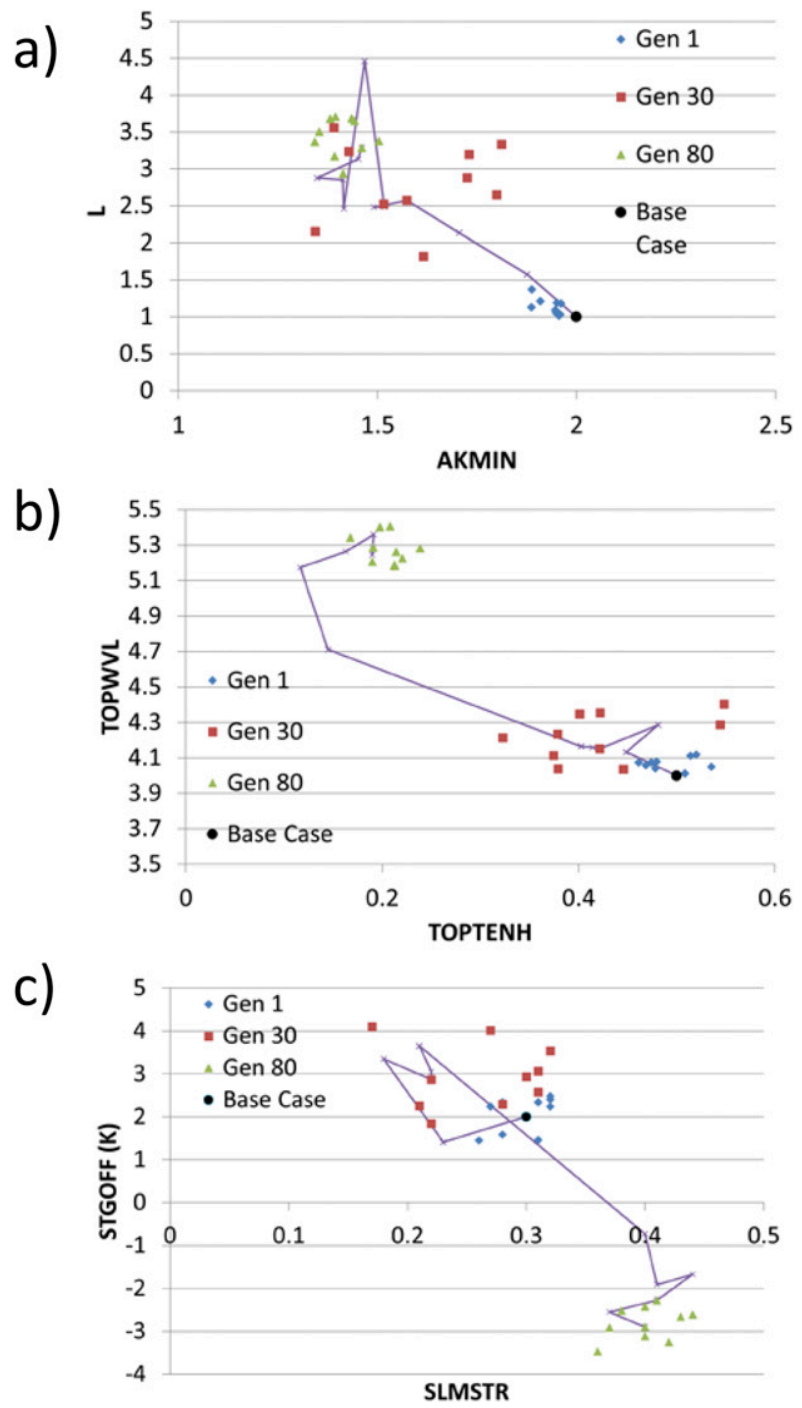

FIG. 9. Path in parameter space (purple line), as directed by the EP process, for (a) length-scale multiplier $L$ vs minimum horizontal diffusion coefficient (AKMIN, grid 1), (b) topographic smoothing multiplier (TOPTWVL) vs silhouette topographic weighting (TOPTENH), and (c) initial soil temperature offset (STGOFF) vs initial soil moisture (SLMSTR). The points indicate the values for the 10 members of each designated generation, with the back circle representing the base case.

will always be available for use in emergency dispersion simulations. An initial investigation of this application has been conducted (Chiswell et al. 2012), and the use of evolutionary programming in an operations setting has great potential.

Acknowledgments. Funding for this study was provided by the U.S. Department of Energy and the Laboratory Directed Research and Development Program at the Savannah River National Laboratory. SRNL is operated by Savannah River Nuclear Solutions for the
U.S. Department of Energy under Contract DE-AC0908SR22470.

\section{APPENDIX A}

\section{Perturbed Parameters}

The model parameters selected for perturbation are listed in Table 1, and all but the last are described in detail in Walko and Tremback (2006). These were selected as they control important model processes-subgrid-scale diffusion, surface forcing, and interaction with the prescribed boundary forcing. They are also fairly "free"that is, they rely on a subjective selection-and it is these parameters that can benefit from an objective process to set optimized values. We provide here a brief description of each one, along with the base case values.

a. AKMIN, grid 1 and AKMIN, grid 2

In the model, unresolved diffusion is accomplished with $K$ theory, in which the parameterized vertical and horizontal fluxes of heat and momentum are related to the resolved gradients in those variables through the use of an eddy diffusivity $K$ term. The model is run with the Mellor-Yamada scheme (Mellor and Yamada 1982) to determine eddy diffusivities in the vertical with the Smagorinsky (1963) horizontal deformation scheme for the horizontal diffusion. For the horizontal diffusivity, the user must subjectively set minimum values of $K$ by setting the value of AKMIN (set to 1.0 in the base case) to prevent nonphysical noise from accumulating.

\section{b. TNUDLAT and TNUDCENT}

The model "nudges" the solution (including the grid interior) toward the parent grid using a Newtonian relaxation term, with the relaxation strength (measured in seconds, with longer relaxation times implying weaker nudging) set by the user. This term will vary from the outer grid edge (TNUDLAT) to the interior value (TNUDCENT). In the base case, these time scales range from $22 \mathrm{~min}$ at the outer edge to $3 \mathrm{~h}$ at the model center.

\section{c. SLMSTR and STGOFF}

The initial values of soil temperature and moisture must be set by the user at each soil level. The soil moisture ranges from a value of 0 (totally desiccated soil) to 1.0 (totally saturated soil). The base case value was set to 0.3. STGOFF represents the "offset," the difference between the temperatures of the soil layer and the lowest atmospheric layer. The base case value was 2.0 (for soil $2.0^{\circ} \mathrm{C}$ warmer than the lowest atmospheric layer.) 


\section{d. TOPTENH and TOPTWVL}

The grid resolutions of 60 and $20 \mathrm{~km}$ are both coarser than the 30 -s topography used in the model. The subgridscale topography is not ignored, however. For each grid cell, the model calculates the "silhouette" height of the topography and then averages this with the overall mean of topography in the grid cell, weighting the silhouette average by the factor TOPTENH (set to 0.5 in the base case). TOPTWVL (set to 4.0 in the base case) controls the smoothing of resolved topography to avoid the generation of noise at the lower boundary [see Walko and Tremback (2006) for more details].

e. $L$

As part of the Mellor-Yamada subgrid-scale vertical diffusion calculation, the model calculates a turbulent length scale, related to the parameterized eddy kinetic energy. This controls the subgrid scale mixing, and a multiplicative factor (set to 1 in the base case) was applied.

\section{APPENDIX B}

\section{Model Evaluation}

The bias $B$ is simply the average difference between paired measurements and predictions. The bias is an estimate of the general overprediction or underprediction of the model $C_{P}$ with respect to the $N$ measurements $C_{O}$ :

$$
B=\frac{1}{N} \sum\left(C_{P}-C_{O}\right) .
$$

An ideal value for $B$ would be 0 .

The geometric-mean bias (MG) is used to test the tendency of the model to predict the values correctly. Over- and underpredictions are given equal weight in this metric and may be expressed as

$$
\mathrm{MG}=\exp \left(\frac{1}{N} \sum \ln C_{O}-\frac{1}{N} \sum \ln C_{P}\right) .
$$

An ideal value of MG would be 1 .

The geometric variance $(\mathrm{VG})$ is used to test the degree of deviation from measurements. As with the geometricmean bias, this metric gives equal weight to over and under prediction and is expressed as

$$
\mathrm{VG}=\exp \left[\frac{1}{N} \sum\left(\ln C_{O}-\ln C_{P}\right)^{2}\right] .
$$

An ideal value of $V G$ would be 1 .
The Pearson's correlation coefficient $R$ is a measure of the strength of the linear relationship between the measurements and the predictions:

$$
R=\frac{\sum\left(C_{O}-\overline{C_{O}}\right)\left(C_{P}-\overline{C_{P}}\right)}{\sqrt{\sum\left(C_{O}-\overline{C_{O}}\right)^{2}} \sqrt{\sum\left(C_{P}-\overline{C_{P}}\right)^{2}}} .
$$

An ideal value for $R$ would be either -1 or 1 .

The factor of exceedance (FOEX) shows the percentage of modeled predictions, which are larger than the observed measurements. This is a good metric to show the tendency to over- or underpredict the data. Assuming $N_{\left(C_{P}>C_{O}\right)}$ represents the number of model overpredictions, the exceedance may be expressed as

$$
\mathrm{FOEX}=\left[\frac{N_{\left(C_{P}>C_{O}\right)}}{N}-0.5\right] \times 100 .
$$

The ideal value for FOEX would be 0 .

The normalized mean square error is a measure of the degree of deviation of the predictions and also weighs over- and underpredictions equally:

$$
\mathrm{NMSE}=\frac{1}{N} \sum \frac{\left(C_{P}-C_{O}\right)^{2}}{\overline{C_{O} C_{P}}} .
$$

The ideal value for NMSE would be 0 .

\section{REFERENCES}

Bakhshaii, A., and R. Stull, 2009: Deterministic ensemble forecasts using gene-expression programming. Wea. Forecasting, 24, 1431-1451, https://doi.org/10.1175/2009WAF2222192.1.

Berner, J., S. Ha, J. P. Hacker, A. Fournier, and C. Snyder, 2011: Model uncertainty in a mesoscale ensemble prediction system: Stochastic versus multiphysics representations. Mon. Wea. Rev., 139, 1972-1995, https://doi.org/10.1175/2010MWR3595.1.

Calastrini, F., and Coauthors, 2012: Desert dust outbreaks over Mediterranean basin: A modeling, observational, and synoptic analysis approach. Adv. Meteor., 2012, 246874, https://doi.org/ 10.1155/2012/246874.

Chiswell, S. R., R. L. Buckley, and D. W. Werth, 2012: Improved characterization of air emission sources using evolutionary ensembles. 10th Conf. on Artificial Intelligence Applications to Environmental Sciences/17th Conf. on Air Pollution Meteorology with the A\&WMA, New Orleans, LA, Amer. Meteor. Soc., TJ12.1, https://ams.confex.com/ams/92Annual/webprogram/ Paper201040.html.

Chou, M.-D., and M. Suarez, 1999: A solar radiation parameterization for atmospheric studies. Tech. Memo. NASA/TM1999-104606, Vol. 15, 38 pp., http:/gmao.gsfc.nasa.gov/pubs/ docs/Chou136.pdf.

Civicioglu, P., 2013: Backtracking Search Optimization Algorithm for numerical optimization problems. Appl. Math. Comput., 219, 8121-8144, https://doi.org/10.1016/j.amc.2013.02.017. 
Cotton, W., and Coauthors, 2003: RAMS 2001: Current status and future directions. Meteor. Atmos. Phys., 82, 5-29, https:// doi.org/10.1007/s00703-001-0584-9.

Draxler, R. R., and G. Hess, 1998: An overview of the HYSPLIT_4 modelling system of trajectories, dispersion, and deposition. Aust. Meteor. Mag., 47, 295-308.

Duan, Q., and Coauthors, 2017: Automatic model calibration: A new way to improve numerical weather forecasting. Bull. Amer. Meteor. Soc., 98, 959-970, https://doi.org/10.1175/ BAMS-D-15-00104.1.

Eckel, F. A., and C. F. Mass, 2005: Aspects of effective mesoscale, short-range ensemble forecasting. Wea. Forecasting, 20, 328 350, https://doi.org/10.1175/WAF843.1.

Galmarini, S., and Coauthors, 2004: Ensemble dispersion forecasting-Part II: Application and evaluation. Atmos. Environ., 38, 4619-4632, https://doi.org/10.1016/j.atmosenv.2004.05.031.

Girardi, F., and Coauthors, Eds., 1998: The European Tracer Experiment. Joint Research Centre, European Commission, EUR Rep. 18143 EN, Office for Official Publications of the European Communities, $108 \mathrm{pp}$.

Grell, G., 1993: Prognostic evaluation of assumptions used by cumulus parameterizations. Mon. Wea. Rev., 121, 764-787, https://doi.org/ 10.1175/1520-0493(1993)121<0764:PEOAUB > 2.0.CO;2.

— , and D. Devenyi, 2002: A generalized approach to parameterizing convection combining ensemble and data assimilation techniques. Geophys. Res. Lett., 29, 1693, https://doi.org/ 10.1029/2002GL015311.

Harrington, J., 1997: The effects of radiative and microphysical processes on simulated warm and transition season Arctic stratus. Department of Atmospheric Science Bluebook 637, Colorado State University, 289 pp.

Haupt, S., 2005: A demonstration of coupled receptor/dispersion modeling with a genetic algorithm. Atmos. Environ., 39, 71817189, https://doi.org/10.1016/j.atmosenv.2005.08.027.

Jones, G., 2002: Genetic and evolutionary algorithms. Encyclopedia of Computational Chemistry, Vol. 2, P. von Ragué Schleyer et al., Eds., Wiley, 1127-1136.

Lin, Y.-L., R. D. Farley, and H. D. Orville, 1983: Bulk parameterization of the snow field in a cloud model. J. Climate Appl. Meteor., 22, 1065-1092, https://doi.org/10.1175/1520-0450(1983) 022<1065:BPOTSF $>2.0 . \mathrm{CO} ; 2$.

Lucas, D., M. Simpson, P. Cameron-Smith, and R. Baskett, 2017: Bayesian inverse modeling of the atmospheric transport and emissions of a controlled tracer release from a nuclear power plant. Atmos. Chem. Phys., 17, 13 521-13 543, https://doi.org/ 10.5194/acp-17-13521-2017.

Mellor, G. L., and T. Yamada, 1982: Development of a turbulent closure model for geophysical fluid problems. Rev. Geophys. Space Phys., 20, 851-875, https://doi.org/10.1029/RG020i004p00851.

Mosca, S., G. Graziani, W. Klug, R. Bellasio, and R. Bianconi, 1998: ATMES II - Evaluation of long-range dispersion models using 1st ETEX release data. EUR17756 EN, Office for Official Publications of the European Communities, $263 \mathrm{pp}$.

Nakanishi, M., and H. Niino, 2004: An improved Mellor-Yamada level-3 model with condensation physics: Its design and verification. Bound.-Layer Meteor., 112, 1-31, https://doi.org/ 10.1023/B:BOUN.0000020164.04146.98.

, and _- 2006: An improved Mellor-Yamada level-3 model: Its numerical stability and application to a regional prediction of advection fog. Bound.-Layer Meteor., 119, 397-407, https:// doi.org/10.1007/s10546-005-9030-8.

O'Steen, L., and D. Werth, 2009: The application of an evolutionary algorithm to the optimization of a mesoscale meteorological model. J. Appl. Meteor. Climatol., 48, 317329, https://doi.org/10.1175/2008JAMC1967.1.

Pielke, R. A., and Coauthors, 1992: A comprehensive meteorological modeling system-RAMS. Meteor. Atmos. Phys., 49, 69-91, https://doi.org/10.1007/BF01025401.

Reynolds, R. W., N. A. Rayner, T. M. Smith, D. C. Stokes, and W. Wang, 2002: An improved in situ and satellite SST analysis for climate. J. Climate, 15, 1609-1625, https://doi.org/10.1175/ 1520-0442(2002)015<1609:AIISAS > 2.0.CO;2.

Roebber, P. J., 2015: Adaptive evolutionary programming. Mon. Wea. Rev., 143, 1497-1505, https://doi.org/10.1175/ MWR-D-14-00095.1.

Saha, S., and Coauthors, 2010: The NCEP Climate Forecast System Reanalysis. Bull. Amer. Meteor. Soc., 91, 1015-1057, https:// doi.org/10.1175/2010BAMS3001.1.

Severijns, C. A., and W. Hazeleger, 2005: Optimizing parameters in an atmospheric general circulation model. J. Climate, 18 3527-3535, https://doi.org/10.1175/JCLI3430.1.

Shutts, G. J., 2005: A kinetic energy backscatter algorithm for use in ensemble prediction systems. Quart. J. Roy. Meteor. Soc., 131, 3079-3102, https://doi.org/10.1256/qj.04.106.

Skamarock, W. C., and Coauthors, 2008: A description of the Advanced Research WRF version 3. NCAR Tech. Note NCAR/ TN-475+STR, 113 pp., https://doi.org/10.5065/D68S4MVH.

Smagorinsky, J., 1963: General circulation experiments with the primitive equations. Part I, The basic experiment. Mon. Wea. Rev., 91, 99-164, https://doi.org/10.1175/1520-0493(1963) 091<0099:GCEWTP>2.3.CO;2.

Stensrud, D. J., J. Bao, and T. T. Warner, 2000: Using initial condition and model physics perturbations in short-range ensemble simulations of mesoscale convective systems. Mon. Wea. Rev., 128 2077-2107, https://doi.org/10.1175/1520-0493(2000)128<2077: UICAMP $>2.0 . \mathrm{CO} ; 2$.

Straume, A. G., 2001: A more extensive investigation of the use of ensemble forecasts for dispersion model evaluation. J. Appl. Meteor., 40, 425-445, https://doi.org/10.1175/1520-0450(2001) $040<0425$ :AMEIOT $>2.0$. CO;2.

Stunder, B., J. Heffter, and R. Draxler, 2007: Airborne volcanic ash forecast area reliability. Wea. Forecasting, 22, 1132-1139, https://doi.org/10.1175/WAF1042.1.

Tewari, M., and Coauthors, 2004: Implementation and verification of the unified NOAH land surface model in the WRF model. 20th Conf. on Weather Analysis and Forecasting/16th Conf. on Numerical Weather Prediction, Seattle, WA, Amer. Meteor. Soc., 14.2A, https://ams.confex.com/ams/84Annual/techprogram/ paper_69061.htm.

van Dop, H., and Coauthors, 1998: ETEX: A European Tracer Experiment; Observations, dispersion modelling and emergency response. Atmos. Environ., 32, 4089-4094, https://doi.org/ 10.1016/S1352-2310(98)00248-9.

Walko, R. L., and C. J. Tremback, 2006: RAMS Regional Atmospheric Modeling System version 6.0: Model input namelist parameters, 64 pp., http://www.atmet.com/html/docs/rams/ ug60-model-namelist-1.4.pdf

Walko, R., and Coauthors, 2000: Coupled atmosphere-biophysicshydrology models for environmental modeling. J. Appl. Meteor., 39, 931-944, https://doi.org/10.1175/1520-0450(2000)039<0931: $\mathrm{CABHMF}>2.0 . \mathrm{CO} ; 2$.

Wang, J., and Coauthors, 2017: Large-scale transport of PM2.5 in the lower troposphere during winter cold surges in China. Sci. Rep., 7, 13238, https://doi.org/10.1038/s41598-017-13217-2.

Werth, D., and R. Buckley, 2017: Characterizing the detectability of emission signals from a North Korean nuclear detonation. 
J. Environ. Radioact., 169-170, 214-220, https://doi.org/ 10.1016/j.jenvrad.2016.12.002.

, — - G. Zhang, R. Kurzeja, M. Leclerc, H. Duarte, M. Parker, and T. Watson, 2017: Quantifying the local influence at a tall tower site in nocturnal conditions. Theor. Appl. Climatol., 127, 627-642, https://doi.org/10.1007/ s00704-015-1648-y.

Yerramilli, A., and Coauthors, 2012: An integrated WRF/ HYSPLIT modeling approach for the assessment of PM2.5 source regions over the Mississippi Gulf Coast region. Air Qual. Atmos. Health, 5, 401-412, https://doi.org/10.1007/ s11869-010-0132-1.

Yumimoto, K., K. Eguchi, I. Uno, T. Takemura, Z. Liu, A. Shimizu, and N. Sugimoto, 2009: An elevated large-scale dust veil from the Taklimakan Desert: Intercontinental transport and threedimensional structure as captured by CALIPSO and regional and global models. Atmos. Chem. Phys., 9, 8545-8558, https:// doi.org/10.5194/acp-9-8545-2009. 